\title{
William Blake: o estudo do processo de criação de um Doppellegabung
}

William Blake: the study of the process of creation of a Doppelbegabung

\author{
Claudia Regina Rodrigues Calado
}

Resumo: William Blake era um Doppelbegabung, ou um artista de talentos múltiplos. Ele demonstrava aptidão para artes imagéticas e verbais, e intencionou juntá-las, inextricavelmente, em Songs of Innocence and of Experience. $O$ presente trabalho tem como objetivo a investigação de como se deu a feitura de tal obra, em que medida textos verbais e pictóricos apresentam-se colocados em uma posição de complementaridade mútua. Buscamos observar, através do estudo de seus manuscritos, se o homem das imagens predominava sobre o homem das letras, ou se era o contrário. Para isso, recorremos à Crítica Genética, campo do conhecimento dedicado ao estudo de processos de criação.

Palavras-chave: William Blake. Doppelbegabung. Processo de Criação.

Abstract: William Blake was a Doppelbegabung, or a multi-talented artist. He demonstrated aptitude for both imagistic and verbal arts and had the intention to join them, inextricably, in Songs of Innocence and of Experience. The present study aims at investigating how such a work was created, with its verbal and pictorial texts put in a mutual complementary position. We tried to observe, through the study of his manuscripts, if the man of images was predominant over the man of words, or the other way around. For so, we resorted to a field of knowledge called Genetic Criticism, which is dedicated to the study of processes of creation.

Keywords: William Blake. Doppelbegabung. Process of Creation.

William Blake foi um poeta, gravador, ilustrador e pintor do século XVIII. Era um caso de Doppelbegabung, denominação de Ulrich Weisstein (1982) para artistas que apresentam talentos múltiplos. Porém, diferente de outros que possuíam essa mesma característica, Blake unia poesia e gravura em um mesmo meio físico. Michelângelo, Dante Gabriel Rossetti e Henry Fuseli, por exemplo, escreviam e pintavam, mas em momentos diferentes, em obras e meios diferentes. Segundo Walter Crane 
Claudia Regina Rodrigues Calado

(1905), quando um artista tem o dom do talento duplo, a interação entre dois meios semióticos específicos produz harmonia. Crane acreditava que Blake era um artista excepcional, que conseguia atingir "harmony between text and illustration. They become a harmonious whole, in complete relation" (1905, p. 139) ${ }^{1}$.

Blake desenvolveu uma técnica de impressão original chamada de Illuminated Printing (impressão iluminada), através da qual gravava poemas e desenhos em uma mesma matriz de cobre. Fez uso desse método para imprimir suas principais obras, que tinham como inconfundível característica a união de verbo e imagem. Contudo, segundo Vaughn (1999), no trabalho iluminado de Blake, as imagens correspondentes a cada poema não eram simplesmente uma reprodução do texto verbal, mas ambas as linguagens se complementavam para formar um todo mais amplo, mais complexo. De fato, percebe-se que o poema ampliava a interpretação da imagem e vice-versa, porém, em alguns de seus últimos trabalhos, o que se lia não correspondia ao que se via, já que imagem e verbo não tinham nenhuma correlação aparentemente coerente. Não se pode dizer, portanto, que Blake ilustrava seus textos verbais, uma vez que este conceito remete ao ato de traduzir o verbal através do não verbal. Ilustrar, nas atuais concepções da atividade, significa traduzir ou ressignificar o texto de partida (ARROJO, 2002); nesse caso, a tradução é considerada independente e, embora mantenha uma relação de anterioridade com o texto fonte, é entendida como outro texto, pois é fruto de outra interpretação. No caso de Blake, o que ele faz é aliar uma linguagem à outra. Cria imagem e verbo para que funcionem juntos, como dois instrumentos dentro de uma mesma orquestra; se estiverem separados farão sentido, mas, se apreciados em conjunto, ampliarão e enriquecerão a interpretação como um todo. Ou seja, ao se separar as duas linguagens, o poder semântico da obra fica comprometido.

Baseados nessa premissa, consideramos que, no trabalho iluminado de Blake, nenhuma das linguagens predomina sobre a outra. Não há uma relação de superioridade do verbo ou da imagem, ambos são igualmente importantes para uma compreensão mais ampla do todo. Porém, como já afirmamos, nem todas as suas obras possuem uma relação íntima referencial entre o verbal e o pictórico. A pesquisadora

1 “[...] harmonia entre texto e ilustração. Eles se tornam um todo harmonioso, em completa relação" (tradução nossa). 
Andréa Lima Alves (2007), em sua tese de doutoramento intitulada A interação entre texto e ilustrações nos illuminated books de William Blake pelo prisma da obra America, a Prophecy, afirma que, nas obras iluminadas de Blake, existem momentos em que esse poder de referencialidade entre as duas linguagens parece maior e momentos em que parece menor. De acordo com a referida autora, há três tipos de classificação quanto à referencialidade: em algumas obras, as gravuras apresentam um grande grau de referência com os textos; em outras, essa relação se dá de maneira metafórica, fazendo com que o leitor interprete as gravuras a partir de analogias; e em outras, essa referencialidade é pequena, pois as imagens não têm correlação com o texto e o leitor se vê obrigado a levantar hipóteses, já que, por exemplo, há a presença de personagens que sequer são mencionados nos textos verbais.

William Blake: o estudo do processo de criação de um Doppelbegabung

Contudo, não se pode negar que Blake une, em grande parte de seu trabalho, poesia e pintura, duas artes consideradas rivais por críticos como W. J. T. Mitchell (1986), para quem textos imagéticos e textos verbais, sob certas perspectivas, apresentarão sempre uma relação de superioridade, ora de um, ora do outro. Este estudioso aponta argumentos que colocam por vezes a imagem em posição de inferioridade em relação ao verbo, por outras o verbo em posição de inferioridade em relação à imagem, enfim, ambas a linguagens em uma relação de desigualdade. Ao contrário, para Blake, poesia e pintura jamais poderiam ser dissociadas, pois ambas seriam frutos do seu ser artístico (VAUGHN, 1999). Isso se reflete em suas composições, no entrelaçamento existente entre o verbo e a imagem. Diante de tal fato, questionamos se, em seu processo de criação, essas duas linguagens também desfrutavam da mesma atenção; ou seja, se Blake dispensava igual importância à criação de ambos os textos, se os criava de maneira simultânea ou se priorizava um deles, fazendo com que algum servisse como ponto de partida para o outro.

Para respondermos a essa indagação, recorremos à fonte de sua criação, nesse caso, aos manuscritos de Songs of Innocence and of Experience shewing the two contrary states of the human soul, que, embora tenha sido publicada como um único e grande signo estético, na verdade foi escrita em duas etapas: Songs of Innocence (Canções da Inocência) em 1789 e Songs of Experience (Canções da Experiência) em 1794. Essa obra, pelas suas características, pertence à primeira classificação de Lima (2007), pois apresenta um alto grau de referencialidade entre os textos verbais e imagéticos; ou seja, verbo e imagem caminham juntos e se correlacionam de maneira imbricada. 
Claudia Regina Rodrigues Calado

Ao ingressarmos no universo dos manuscritos da obra supracitada, deparamo-nos com um campo de estudo chamado Crítica Genética, que se volta para os processos de criação em geral, propondo uma abordagem sistêmica ao estudo destes, ao mesmo tempo em que procura entender de que maneira se dá a interação entre os documentos de processo analisados. Em suma, os estudos genéticos nos permitem analisar, a partir de manuscritos, os percursos da criação. Manuscritos, para os geneticistas, são documentos que auxiliam o pesquisador a fazer inferências e levantar hipóteses ou postulados baseados nas marcas deixadas pelo autor: omissões, acréscimos, apagamentos etc. A importância de um estudo genético reside no seu propósito de tornar visível e compreender a originalidade de um texto através do processo que o fez surgir.

Os estudos genéticos propõem uma abordagem sistêmica para que se possa entender a criação como ação comunicativa, que acontece em rede e interliga sujeito, processo de criação e contexto sociocultural. Para desenvolvermos tal estudo, analisamos os manuscritos contidos no notebook de Blake, que contém poemas, gravuras e desenhos; a partir daí, buscamos entender o seu processo de criação. Segundo Anastácio e Silva (2010), os documentos de processo nos dão bases empíricas para inferirmos sobre os caminhos trilhados pelo artista, considerando que o processo de criação sofre influências múltiplas, tais como: de outros criadores, da família, do contexto sociocultural, dentre outras. Estes são os chamados subsistemas de um sistema maior em que se insere a obra do autor, podendo fazer parte desse subsistema as rasuras, os erros, os fragmentos de manuscritos, as cartas, os diários, as anotações. Como afirma Pino (2007)²:

\footnotetext{
É importante perceber que o objeto da Crítica Genética não é um texto, um material, mas um processo, não aquele pelo qual o escritor passou, mas aquele que o pesquisador construiu a partir dos manuscritos que esse escritor deixou.
}

Cecília Almeida Salles (2008) comenta que a Crítica Genética nasce da constatação de que uma obra é resultado de um trabalho que passa por transformações progressivas. Surge a partir de um investimento

2. Disponível em: <http://cienciaecultura.bvs.br/scielo.php?pid=S0009-67252007000100013\&script=sci_arttext>. Acessado em 03 de outubro de 2014. 
de tempo, dedicação e disciplina por parte do autor; entretanto, passa por um processo de correções, de pesquisas, de esboços que desdizem aquele velho mito romântico de que a obra já nasce pronta. $O$ interesse da Crítica Genética está voltado para o processo criativo e trata-se de uma investigação que indaga a obra de arte a partir de sua fabricação, a partir de sua gênese. Como é criada uma obra? Essa é sua grande questão. Outras áreas, como a Filologia, por exemplo, vêm estudando o manuscrito literário, mas o que diferencia a Crítica Genética é seu interesse centralizado na compreensão do processo de criação em si. Segundo Salles (2006, p. 19), o pesquisador move-se sobre as "pegadas" do autor, tendo diante de si a criação, que, para ela, é dinâmica. Esse dinamismo permite que o pesquisador entre em contato com todas as possibilidades que tenham surgido no decorrer do processo da criação: William Blake: o estudo do processo de criação de um Doppelbegabung as interferências de outras obras, as interferências de obras do próprio autor sobre aquela nova que está sendo construída e todos os possíveis desencadeamentos que poderiam ter ocorrido. Essa constatação leva Salles (2004) à noção de "inacabamento", ideia inversa ao que se pode chamar de "obras completas" ou "ideais".

A questão da "essência" também se enfraquece quando se vê uma obra como um espaço de variações contínuas, de possíveis interpretações e infinitas modificações. Segundo Salles (2006), Peirce já afirmava que seria impossível capturar o objeto dinâmico por inteiro, ou seja, capturar a essência ou a verdade total de um trabalho artístico. Mesmo porque o conceito de verdade também é questionável e relativo, ele depende do ângulo que se escolhe para descrever um fenômeno. O que se consegue é apenas ter acesso a um recorte dessa possível verdade, que Peirce (1990) chama de objeto imediato.

Ainda segundo Salles (2006, p. 21): "Não se trata de uma desvalorização da obra entregue ao público, mas da dessacralização dessa como produto final e única forma possível". Muitas vezes, o pesquisador de Crítica Genética depara-se com registros "finais" de um romance, por exemplo, marcados por índices de insatisfação por parte do autor com relação a seu texto. Ou seja, talvez nem mesmo para o próprio escritor, a obra estivesse "acabada", mas tinha que ser entregue para publicação, por isso ele a dá por terminada.

Diante dessa perspectiva, é possível entendermos que o processo de criação não se dá de maneira linear, o que nos leva novamente ao conceito de rede. Para as autoras Silva e Anastácio (2010), a criação 
Claudia Regina Rodrigues Calado

se dá de maneira interacional, em que podemos observar um diálogo entre autores, entre manuscritos, entre obras, ou seja, há um contínuo de relações que constitui a atividade criadora. $\mathrm{O}$ sistema criativo, por ser aberto, apresenta três propriedades: a globalidade (em um sistema aberto as partes são interdependentes e qualquer mudança em uma parte implicará em mudança no sistema); a retroalimentação (as relações entre os elementos do sistema são circulares e qualquer interferência no sistema poderá atingir sua totalidade); e a equifinalidade (por ser um sistema circular, os resultados finais podem ser alcançados de diferentes maneiras e a partir de condições iniciais diferentes).

Assim, o pensamento criativo é ativado por elementos intrínsecos e extrínsecos ao próprio sistema que está sendo construído, e o que o crítico genético deve fazer é estabelecer conexões a partir do material estudado e buscar entender a rede de associações inerente ao pensamento do autor. De acordo com Salles (2006, p. 33), "O que buscamos é a compreensão da tessitura desse movimento; para assim entrar na complexidade do processo".

Nosso corpus se constituiu de dois fólios (unidade de um caderno manuscrito) onde se encontram rascunhos de três poemas de Songs of Innocence e que estão contidos no manuscrito incompleto An Island in the Moon, editado e comentado por Michael Phillips em seu livro The Creation of the Songs: from manuscript to Illuminated Printing (2000). Ainda tivemos acesso à versão fac-símile do caderno de anotações de Blake (notebook), como já mencionamos anteriormente, que foi editado, comentado e transcrito por David Erdman e Donald Moore em 1973, e que contém manuscritos referentes a vinte e um poemas de Songs of Experience. Esse notebook está repleto de textos verbais e de desenhos (quando seu irmão Robert morreu em 1787, Blake começou a usar as páginas em branco do livro de rascunhos dele como se fosse seu, enchendo-o de rabiscos até que o caderno estivesse completamente utilizado, em 1818). O notebook contém rascunhos preliminares a maioria das Canções da Experiência (com exceção de três delas), de outros poemas nunca publicados, alguns epigramas, rascunhos de poesia filosófica, versos não escritos para publicação, rascunhos de textos em prosa, desenhos preliminares de trabalhos publicados, bem como muitos outros esboços e tentativas variadas. Muitas vezes, Blake simplesmente usava seu notebook como um diário para desabafo. Esse documento é muito importante para o estudo do seu processo de criação, pois podemos encontrar poemas 
revisados exaustivamente, como por exemplo, "London", "Infant Sorrow" e "The Tyger". Todos os fólios desse caderno estão catalogados com a letra $\mathrm{N}$ seguida da numeração correspondente, na mesma sequência em que ia sendo usado por Blake.

Importante também para o nosso estudo foi a marginália registrada nesse mesmo documento de processo. Blake ali anotou muitas de suas impressões e amarguras, algo que muitos outros criadores talvez sintam, mas nem sempre registrem. Durante os anos em que sua obra mais extensa, Jerusalem, estava sendo finalizada (1804-1820), ele escreveu os parágrafos octossílabos de outra obra, The Everlasting Gospel (1820), em determinados espaços do seu notebook (MARGOLIOUTH, 1951). Isso explica porque, em seus manuscritos, há a presença tão fecunda de anotações paralelas que nada têm a ver com o que está sendo criado naquele fólio.

Blake também tinha como hábito fazer anotações nas margens dos livros que lia. Ele anotava tanto que, muitas vezes, não sobrava nenhum espaço em branco nas páginas. Catherine Blake, sua esposa, afirmou que nunca o via com as mãos desocupadas. Mesmo quando estava lendo, segundo ela, Blake fazia anotações que externavam suas opiniões (MARGOLIOUTH, 1951). Muitas interpretações e opiniões sobre o artista foram repensadas simplesmente depois de se ter lido sua marginália, como por exemplo, de que era louco e mal instruído, ou de que era obscuro, ou ainda que tinha um temperamento calmo e doce. 0 que se pode perceber nitidamente é que Blake era estimulado pelas obras de outros autores a escrever e anotar suas ideias e impressões, o que se constitui um rico material para o estudo do artista.

Outro recurso que tivemos acesso para nosso estudo foram os desenhos que ele esboçou, mas não necessariamente publicou, e que estão contidos na obra Drawings of William Blake: 92 pencil studies, comentada e selecionada por Sir Geoffrey Keynes (1970). Pensamos que esse material foi extremamente importante para entendermos a dinâmica do processo de criação do artista, pois nos auxiliou a fazer inferências mais ancoradas, mais seguras.

Salles (2002) afirma que um geneticista pode se defrontar com os diferentes suportes materiais para a realização de seu trabalho: cadernos de anotações, diários, correspondências, roteiros, mapas, planos, esboços, primeiras redações, rascunhos, manuscritos (como os originais são chamados), datilografia e provas de impressão. Ainda segundo Salles, é na relação entre o pesquisador e seu objeto de estudo, ou seja, o material enquanto documento observado, que se pode falar da Crítica Genética como construção intelectual, como texto que foi constituído pelo próprio crítico genético. 
Claudia Regina Rodrigues Calado

Dos 3 fólios do manuscrito An Island in the Moon e dos 113 fólios atribuídos a Blake no Manuscript Notebook, 93 carregam textos verbais e imagéticos. São geralmente desenhos cobertos com textos verbais ou cercados por eles. Podemos perceber que a co-presença das duas linguagens é predominante na raiz de sua criação, embora praticamente não haja uma associação entre elas. Diferentemente do que acontece na obra que podemos chamar de verbo-pictórica Songs of Innocence and of Experience, em que vemos uma integração entre textos verbais e imagéticos, nos rascunhos, quando essas duas modalidades de texto se encontram em um mesmo fólio, essa relação não existe. Blake buscava uma integração entre as duas artes, mas elas não eram criadas simultaneamente, embora o artista se esforçasse por integrá-las em suas obras, atribuindo, em última instância, características imagéticas às letras. Destacamos, por exemplo, o caso de "The Tyger" (fig. 01), em que, ao escrever o poema deliberadamente com a letra $\mathbf{Y}$, ao invés do uso convencional do I, Blake atribui uma característica imagética, plástica, ao verbo, já que o formato de $\mathrm{Y}$ remete à cauda do animal; essa característica é reforçada pela maneira como o autor ondula a letra de forma a dar movimento a essa mesma cauda. Outras indicações dessa mistura entre as linguagens são os galhos da árvore que separam as estrofes, ou as ramas no chão que sobem e se unem às letras do título.

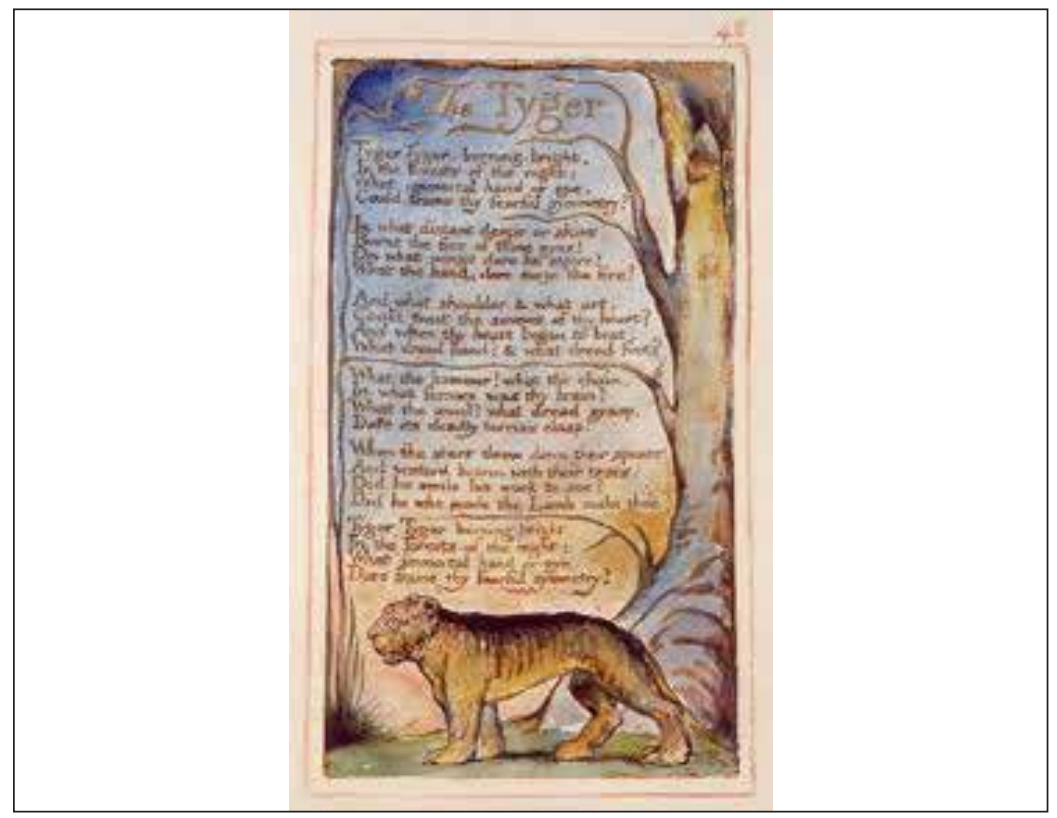

Fig. 01 - Matriz de "The Tyger"

Fonte: Blake, 2008, p. 84 
Porém, apesar dessa união entre verbo e imagem ser bem clara em suas obras "prontas", raramente o que estava escrito nos fólios correspondia aos desenhos feitos neles; estes eram geralmente criados em um momento anterior, de maneira centralizada, e respeitados no sentido de que Blake esforçava-se para não os encobrir com suas escrituras. $O$ artista os contornou com suas anotações, seus poemas, suas observações, seus epigramas ou comentários, mas de maneira que eles fossem mantidos visíveis. Talvez isso acontecesse por causa de uma constatação que fizemos: Blake tinha como característica em seu processo de criação a antecipação da temática de seus poemas através de desenhos. São muitos os casos em que ele esboçou o texto imagético para, somente anos depois, desenvolver o verbal que seria seu correspondente. Essa tendência já aparece no fólio $16 \mathrm{v}$ (fig. 02) do manuscrito An Island in the Moon, que embora seja datado

William Blake: o estudo do processo de criação de um Doppelbegabung de aproximadamente 1785, contém o desenho de um leão deitado com um cordeiro recostado sobre sua barriga, personagem que aparecerá em Songs of Experience, em 1794. Vários outros exemplos aparecem também no Manuscript Notebook; a própria disposição de fólios neste manuscrito nos dá tal indicação, pois muitos motivos e personagens da obra aparecem como desenhos na sua primeira metade e como textos verbais somente na segunda.

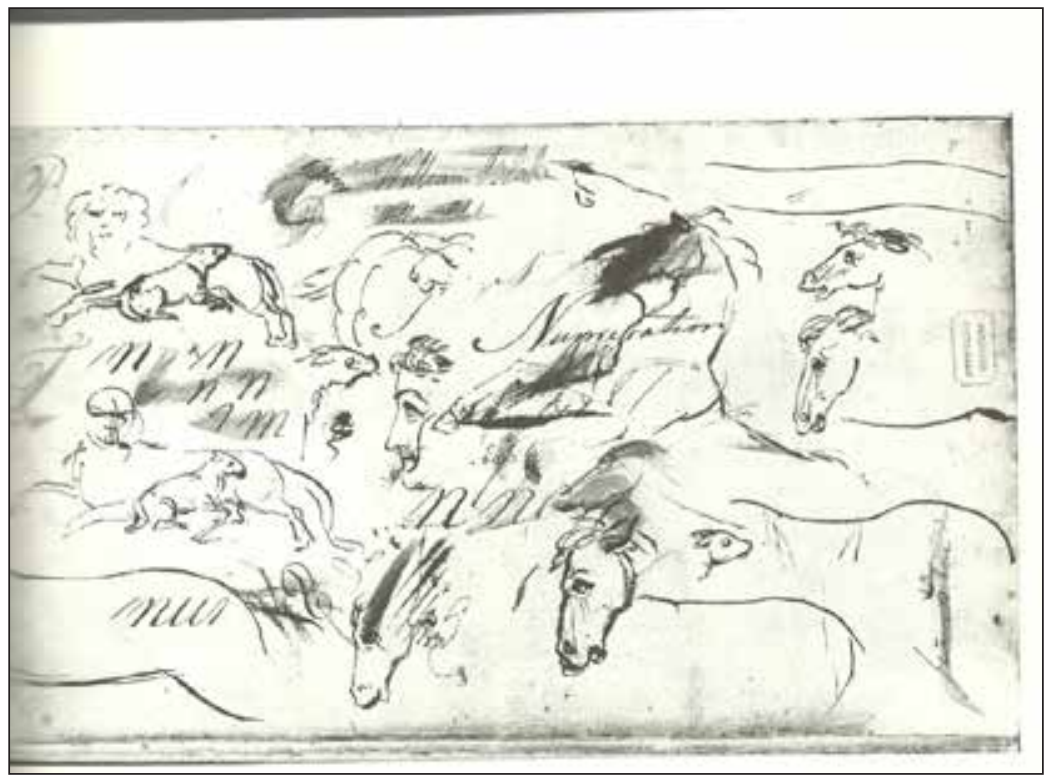

Fig. 02 - Fólio 16v do manuscrito An Island in the Moon Fonte: Phillips, 2000, p. 17 
Claudia Regina Rodrigues Calado
Outros exemplos dessa antecipação temática são: o tigre, que aparece desenhado no fólio N2 (fig. 03), será usado em “The Tyger”, poema cujos rascunhos só aparecerão em N109; o desenho da mãe olhando para o filho morto no fólio N74 (fig. 05) será usado em "Holy Thrusday", cujo texto verbal aparece rascunhado somente em N103 (fig. 06); a figura humana deitada com a cabeça entre as pernas, em N74 (fig. 05), e a figura humana que emerge da rosa doente nos fólios N21 (fig. 07) e N74 (fig. 05), aparecerão em "The Sick Rose", cujo texto verbal será rascunhado em N107 (fig. 8); a mulher sentada curvando-se com a cabeça abaixada, também no fólio N74 (fig. 5), é uma construção imagética de "My Pretty Rose Tree", cujo texto verbal será rascunhado em N115 (fig. 09); o velho viajante, que primeiro aparece fugindo apressado em N15 (fig. 10), depois se olhando no espelho como a caracterização da Morte em N17 (fig. 11), e finalmente como a própria Morte carregada pelas mãos de uma criança em N54 (fig. 12), são personagens que comporão o texto imagético de "London", cujo texto verbal será rascunhado em N109 (fig. 04), e também irão compor uma das matrizes de Jerusalém, obra de 1804; a cena da morte de um casal com duas pessoas (provavelmente seus filhos) chorando ao lado de seus corpos deitados em uma cama, que aparece em N43 (fig. 13) e depois será usada como página-título de Songs of Experience; o anjo retratado em N65 (fig. 14) será usado como texto imagético em "The Angel”, cujo texto verbal é rascunhado em N103 (fig. 6); a mulher deitada sobre um divã em N57 (fig. 15) será o tema central de "Introduction" (poema que não foi rascunhado no notebook). 


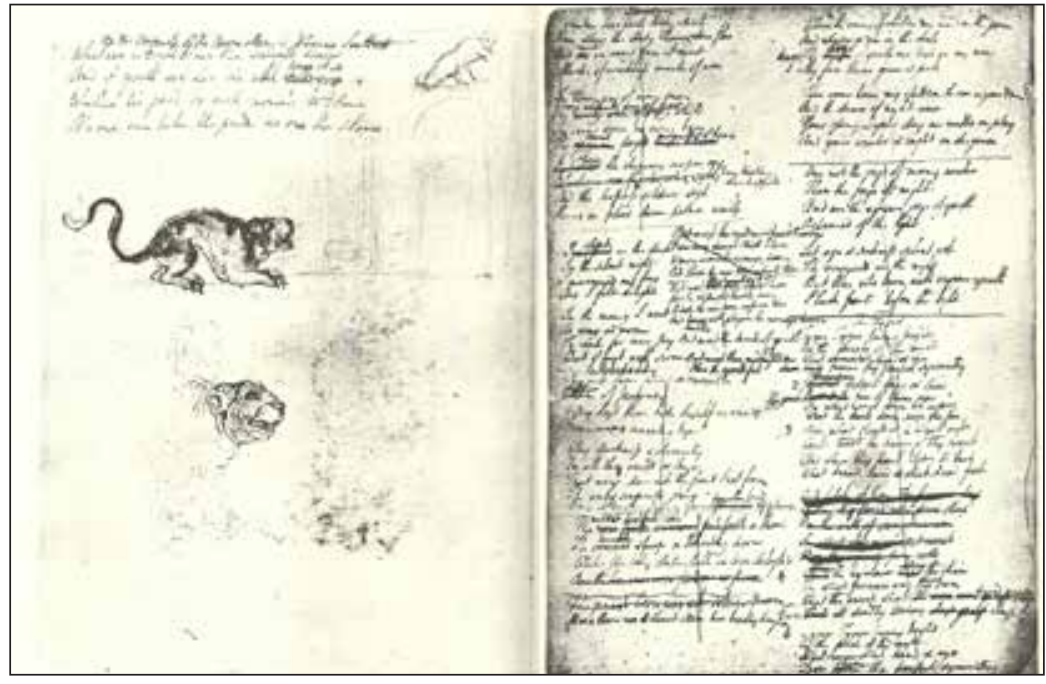

William Blake: o estudo do processo de criação de um Doppelbegabung

Fig. 03 - Fólio N2

Fonte: Blake, 1973, p. 68
Fig. 04 Fólio N109

Fonte: Blake, 1973, p. 283

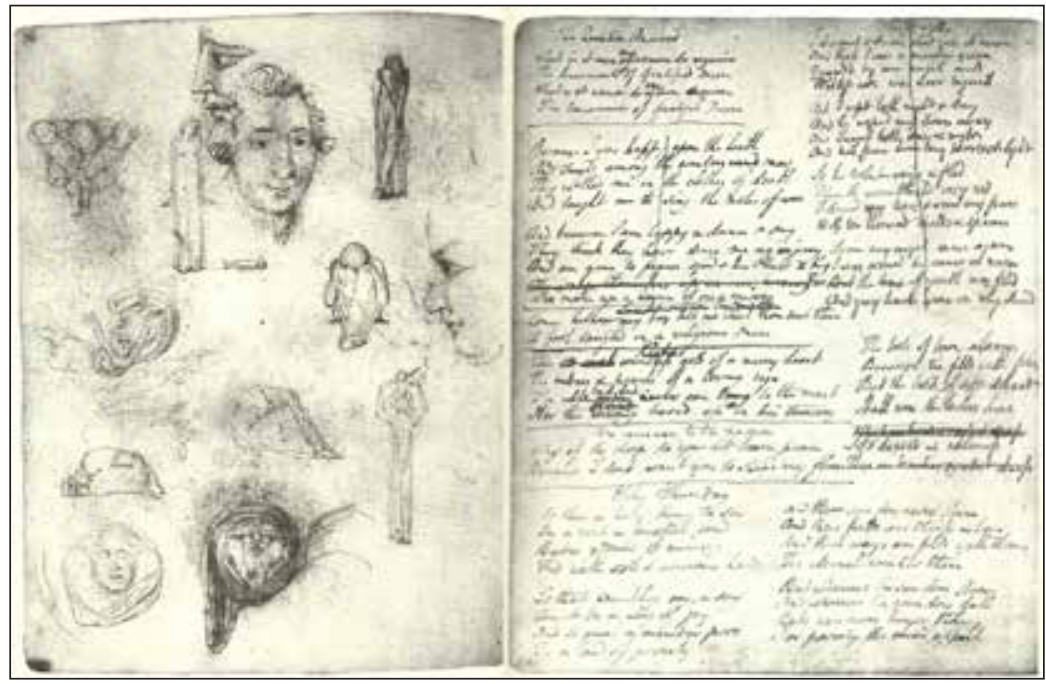

Fig. 05 - Fólio N74

Fonte: Blake, 1973, p. 212
Fig. 06 - Fólio N103

Fonte: Blake, 1973, p. 271 


\section{Claudia Regina \\ Rodrigues Calado}

46

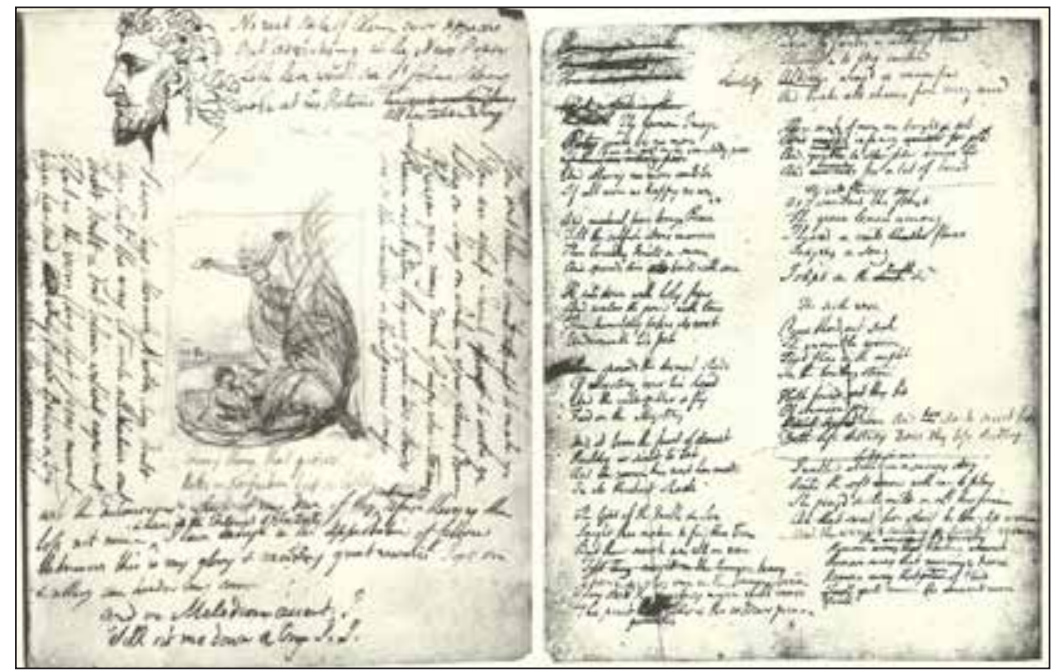

Fig. 07 - Fólio N21

Fonte: Blake, 1973, p. 107

Fig. 08 - Fólio N107

Fonte: Blake, 1973, p. 279

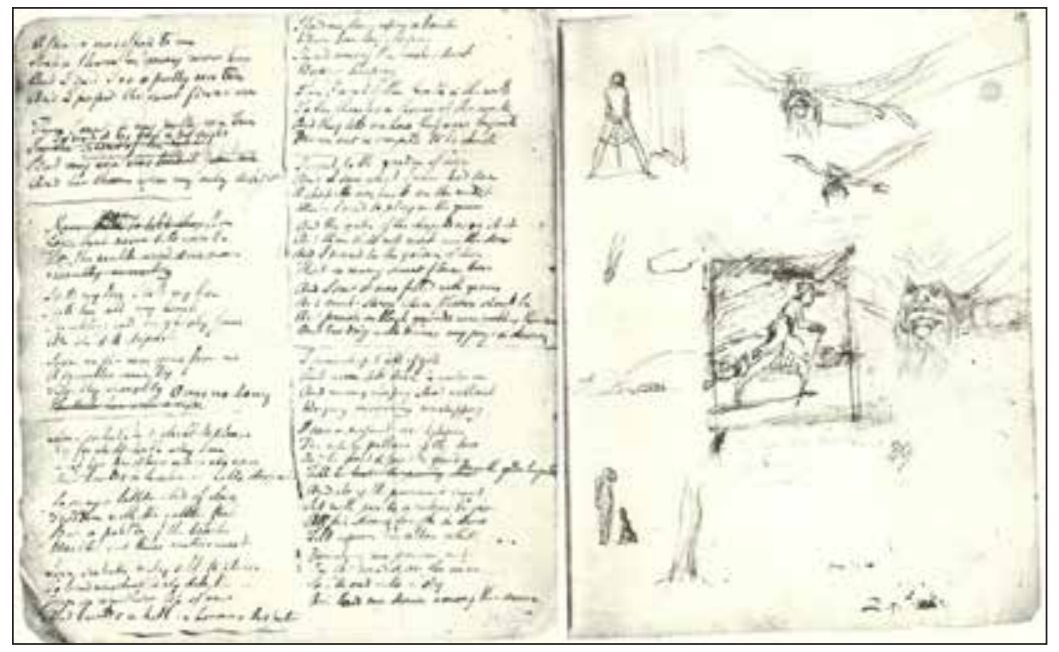

Fig. 09 - Fólio N115

Fonte: Blake, 1973, p. 295
Fig. 10 - Fólio N15

Fonte: Blake, 1973, p. 95 


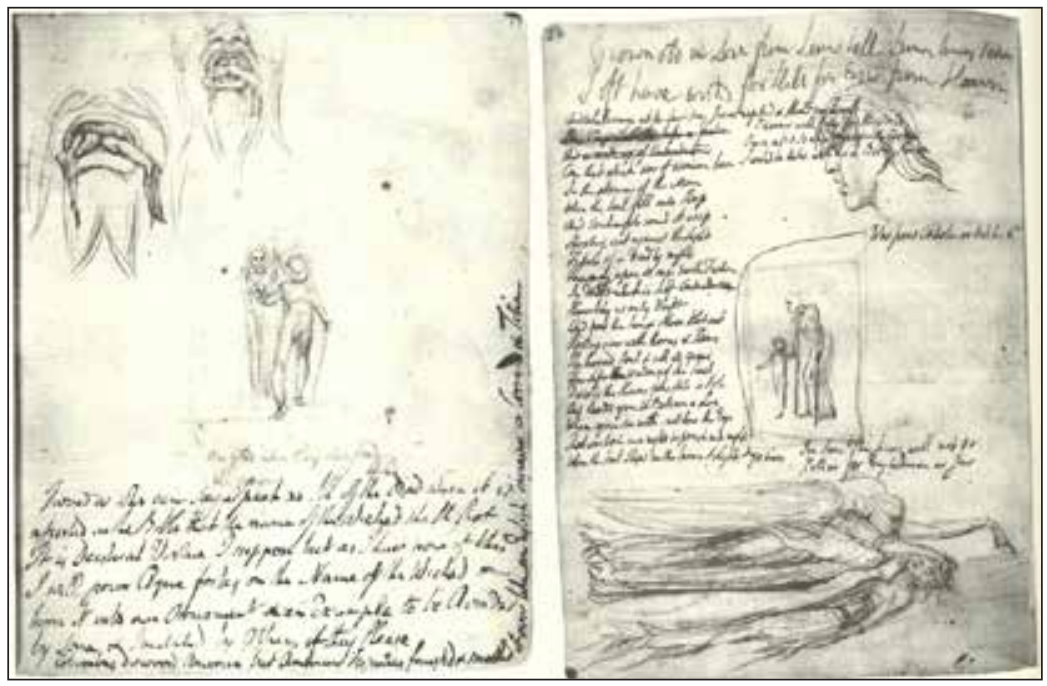

William Blake: o estudo do processo de criação de um Doppelbegabung

Fig. 11 - Fólio N17

Fonte: Blake, 1973, p. 99
Fig. 12 - Fólio N54

Fonte: Blake, 1973, p. 172

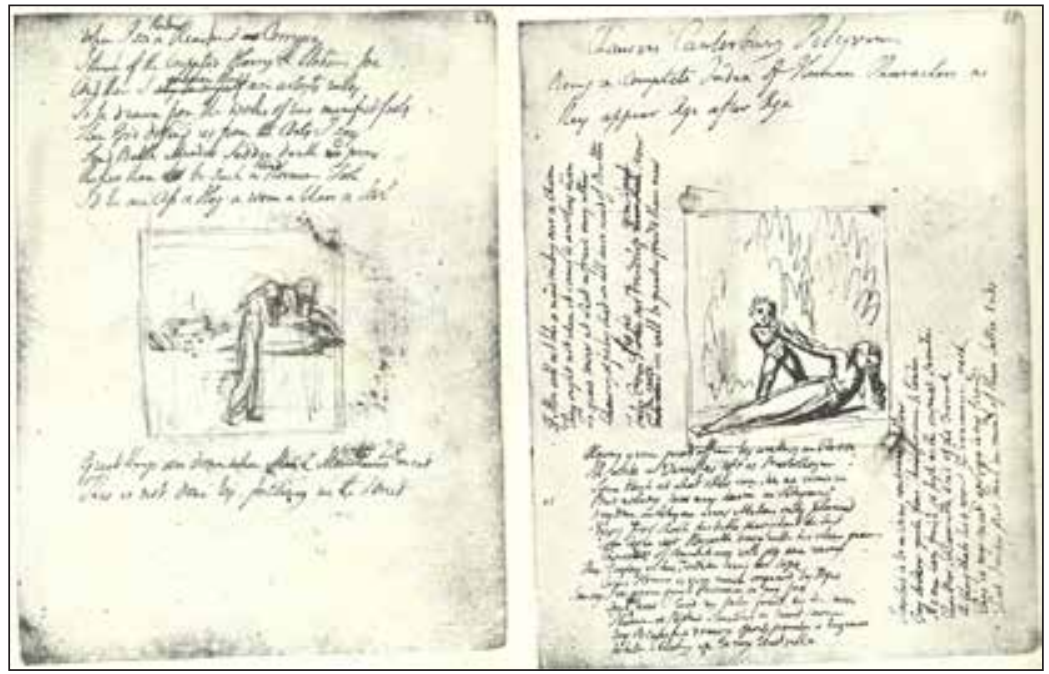

Fig. 13 - Fólio N43

Fonte: Blake, 1973, p. 151
Fig. 14 - Fólio N65

Fonte: Blake, 1973, p. 195 


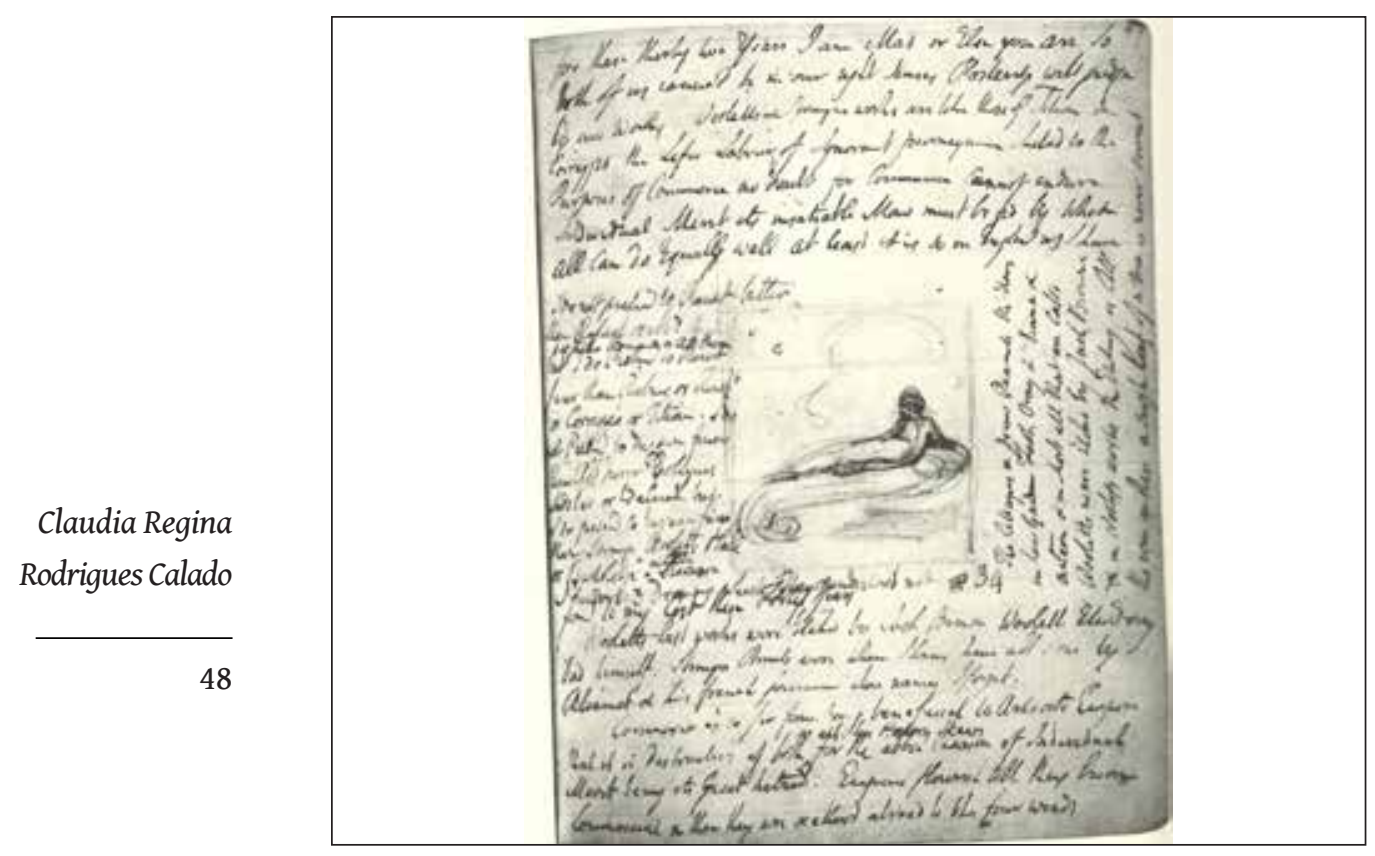

Fig. 15 - Fólio N57

Fonte: Blake, 1973, p. 179

Sugerimos, portanto, que o gravador e o desenhista eram os primeiros a entrar em ação, para só então o poeta se manifestar. Este parecia ser o esquema de sua mente criadora: ele primeiro visualizava mentalmente a obra, desenhava seu texto imagético e desenvolvia, posteriormente, um texto verbal correspondente, se fosse o caso. Afirmamos, então, que os textos imagéticos relativos a Songs of Innocence and of Experience foram criados provavelmente antes dos textos verbais.

Esse tipo de procedimento não aconteceu só com Blake. Muitos autores trabalham as imagens de maneira similar e as usam como possíveis arsenais para suas criações. Silvia Anastácio (1999, p. 18), ao estudar os manuscritos da escritora americana Elizabeth Bishop, fala de imagens geradoras, que "vão alimentando e nutrindo o crescimento de ideias nos seus poemas". Cecília Salles (2010), analisando os manuscritos da obra Não Verá País Nenhum, de Ignácio de Loyola Brandão, observa que este autor tem um pensamento visual, ou seja, seu processo de apreensão dos fenômenos do mundo se dá através de imagens. Segundo a autora, ele desenvolve diagramas visuais que parecem: 
[...] desempenhar um papel importante no modo de desenvolvimento da obra em construção: a condensação da visualidade passa por um processo de expansão quando traduzida verbalmente. Seria um modo de pensar que se organiza com o auxílio da visualidade (SALLES, 2010, p. 103).

No caso de Blake, seus primeiros insights pareciam ser visuais e imaginativos, mas os desenhos não somente faziam parte dos percursos da própria criação; ou seja, não funcionavam apenas como instrumentos para o desenvolvimento de seu pensamento, mas eram também parte da própria obra. Não eram transitórios ou somente geradores, mas complementares aos seus textos verbais correspondentes, mesmo que passassem anos separados para só posteriormente serem unidos.

William Blake: o estudo do processo de criação de um Doppelbegabung

\section{REFERÊNCIAS BIBLIOGRÁFICAS}

ALVES, Andréa Lima. A interação entre texto e ilustrações nos Illuminated Books de William Blake pelo prisma da obra América, a Prophecy. Tese (Doutorado em Teoria e História Literária). Instituto de Estudos da Linguagem, Universidade Estadual de Campinas. Campinas-SP, 2007.

ANASTÁCIO, Silvia Maria Guerra. o jogo das imagens no universo da criação de Elizabeth Bishop. São Paulo: Annablume, 1999.

ARROJO, Rosemary. Oficina de tradução: a teoria na prática. 4. ed. São Paulo: Ática, 2002.

BLAKE, William. The notebook of William Blake: a photographic and typographic facsimile. Edição de David Erdman e Donald Moore. Oxford: Clarendon Press, 1973.

The Complete Illuminated Books. Introdução de David Bindman. Londres: Thames and Hudson, 2008.

CRANE, Walter. of the decorative illustration of books old and new. London: George Bell \& Sons, 1905. 
KEYNES, Sir. Geoffrey. Drawings of William Blake: 92 pencil studies. New York: Dove Publication, 1970.

MARGOLIOUTH, Herschel Maurice. William Blake. London: Oxford University Press, 1951.

MITCHELL, William J. Thomas. Iconology, image, text, ideology. Chicago: University of Chicago, 1986.

Claudia Regina Rodrigues Calado
PEIRCE, Charles Sanders. Semiótica. Trad. José Teixeira Coelho Neto. São Paulo: Perspectiva, 1990.

PHILLIPS, Michael. William Blake, the creation of the songs: from manuscript to illuminated printing. New Jersey: Princeton University Press, 2002.

PINO, Claudia Amigo. Apresentação: genênese da gênese. Ciência e Cultura, vol.59, n.1 São Paulo Jan./Mar, 2007. Disponível em: <http:// cienciaecultura.bvs.br/scielo.php?pid=S0009-67252007000100013\&script $=$ sci_ arttext>. Acesso em: 3.out..2014.

SALLES, Cecília Almeida. Crítica Genética e semiótica: uma interface possível. In. ZULAR, Roberto (org.). Criação em processo: ensaios de crítica genética. São Paulo: Iluminuras, 2002.

. Gesto Inacabado: processo de criação artística. São Paulo: FAPESP: Annablume, 2004.

Redes da criação: construção da obra de arte. São Paulo:Horizonte, 2006.

- Crítica genética: fundamentos dos estudos genéticos sobre o processo de criação artística. São Paulo: EDUC, 2008.

. Arquivos de criação: arte e curadoria. São Paulo: Horizonte, 2010. 
SILVA, Célia Nunes; ANASTÁCIO, Śllvia Maria Guerra. Uma visão sistêmica do processo criador. Revista Manuscrítica, São Paulo: Humanitas, n. 17, 2010.

VAUGHAN, William. William Blake. New Jersey: Princeton University Press, 1999.

WEISSTEIN, Ulrich. Literature and the visual arts. In: BARRICELLI, Jean-Pierre; GIBALDI, Joseph (eds.). Interrelations of literature. New York: MLA, 1982.

Recebido em 10 de setembro de 2015 Aceito em 10 de novembro de 2015

William Blake: o estudo do processo de criação de um Doppelbegabung 51 